\title{
Increased risk of lung cancer among different types of professional drivers in Denmark
}

\author{
Johnni Hansen, Ole Raaschou-Nielsen, Jørgen H Olsen
}

\begin{abstract}
Objectives-To study risk of lung cancer among groups of professional drivers probably exposed to different levels of traffic exhaust fumes.

Methods-A nationwide case-control study (1970-89) based on employees comprising 28744 men with primary lung cancer and incidence density sampled matched controls (1:1). Employment histories were reconstructed back to 1964 for each study subject from the records of a nationwide pension scheme with compulsory membership. Socioeconomic status was derived from the individual job title taken from the national population registry. Information on tobacco smoking habits was available from historical surveys. Relative risks were estimated by odds ratios (ORs) based on conditional logistic regression analyses.

Results-In total 2251 of the male lung cancer cases had been employed as bus, lorry, taxi, or unspecified drivers. No significant difference in tobacco smoking habits was found among professional male Danish drivers and the total employed population. The $O R$ for lung cancer adjusted for socioeconomic status was $\mathbf{1 . 6}$ (95\% confidence interval (95\% CI) 1.2 to 2.2) among taxi drivers, who were considered to be exposed to the highest concentrations of vehicle exhaust fumes, and $\mathbf{1 . 3}$ (1.2 to 1.5) for bus and lorry drivers. The OR was 1.4 (1.3 to 1.5$)$ for unspecified drivers. The adjusted risk of lung cancer increased significantly with increasing duration of employment as a driver, and the risk was highest for long term taxi drivers with 10 years of lag time (OR 3.0; 1.2 to 6.8 ).

Conclusion-Occupational factors, probably exposure to vehicle exhaust, seems to play an important part in the development of lung cancer among drivers.

(Occup Environ Med 1998;55:115-118)
\end{abstract}

Keywords: lung cancer; air pollution; transportation workers

The traffic density is increasing in most countries, and vehicle exhaust fumes have become one of the main sources of air pollution in many cities. ${ }^{1}$ Traffic exhaust is suspected to cause lung cancer in humans: working groups convened by The International Agency for Research on Cancer reviewed the scientific literature and classified diesel and gasoline engine exhaust as, respectively, probably and possibly carcinogenic to humans. Experiments in animals provided sufficient evidence for carcinogenicity, whereas the evidence from epidemiological studies was considered to be limited for diesel exhaust and inadequate for gasoline exhaust. ${ }^{2}$ Further, several components of gasoline and diesel fuels and related combustion products are suspected to be lung carcinogens, including lead, formaldehyde, polyaromatic hydrocarbons, and some nitroarenes. ${ }^{2}$

Epidemiological studies of professional drivers may provide a good basis for evaluating whether air pollution related to traffic involves a carcinogenic risk to humans, as drivers are exposed to traffic exhaust fumes at significantly higher concentrations ${ }^{3-7}$ than the general urban population. Furthermore, taxi drivers spend more time in city traffic, where the pollution is highest, than bus and lorry drivers who cover the entire road grid, including suburban and rural areas. ${ }^{89}$ Even within metropolitan areas, the concentrations of pollutants may be higher inside cars than inside buses. ${ }^{10-12}$

Many of the published studies on exposures to traffic exhaust and the risk of lung cancer were relatively small, and the results were often not adjusted for socioeconomic differences between drivers and the comparison population; most did not attempt to consider possible dose-effect relations. Furthermore, interpretation of results from case-control studies is generally limited by the possible occurrence of information bias. The present population based case-control studies of lung cancer and mesothelioma among professional male drivers takes advantage of the opportunity in Denmark to link accurate and exhaustive information from national registers on cancer and employment histories.

\section{Material and methods}

LUNG CANCER

A total of 37597 men born in the period 1897-1966 in whom a first primary lung cancer was diagnosed in 1970-89, were identified through the Danish Cancer Registry, which provided information on diagnosis from the international classification of diseases seventh revision (ICD-7), name, sex and unique personal identification number. ${ }^{13}$ Past employments were ascertained by record linkage with the files of a nationwide pension fund, adherence to which has been compulsory for all wage earners in Denmark aged 18-66 years since its establishment in 1964. The fund scheme retains computerised information about each employment including the name and personal identification number of the employee, the dates of start and end of the 
employment, and the company name and unique company number of the employer. ${ }^{14}$ This information is kept even after the employees have retired or died. The current job titles of cases were retrieved from the Danish Central Population Registry (CPR), established in 1968, by linkage with the personal identification number. No employment records existed for 8853 patients with lung cancer, who were mainly self employed or permanently out of the workforce, leaving 28744 cases with employment histories.

Control subjects (1:1) were randomly selected from the files of the CPR and were identified by name, sex, present job title, and personal identification number. They were matched to cases on year of birth and sex. Furthermore, they had to be alive without cancer and to have been an employee before the date of diagnosis of the corresponding case. The employment histories of control subjects were retrieved from the files of the pension fund in exactly the same way as for the cases. The principles of the entire data linkage process have been described in detail elsewhere. ${ }^{14}$

Each company in Denmark is classified into one of 700 trade categories by the National Bureau of Statistics according to an extended version of the international standard industrial classification of all economic activities ${ }^{15}$ including activities as taxi driving (71132-33), bus operation (71121-22, 71131) and local or long distance lorry driving (71141-43). On the basis of the information from the pension fund, we identified 1640 lorry or bus drivers, and 426 taxi drivers. These two groups were further subdivided according to their duration of employment: $<6$ months, 6 months -1 year, $1-5$ years, and $>5$ years. Also, drivers working in companies with main activities other than those already mentioned were identified by the job title available from the CPR. These people were classified as unspecified drivers. As CPR does not keep historical information on the occupational titles, the duration of employment was not available for the last group.

\section{MESOTHELIOMA}

Drivers are sometimes engaged in automobile repair work and may be exposed to asbestos when removing brake linings. ${ }^{16}$ Asbestos causes both lung cancer and pleural mesotheliomas. ${ }^{17}$ To evaluate the extent of asbestos exposure, we also investigated the risk for mesothelioma within the same groups of professional drivers with the same procedures as for lung cancer. In total, 550 men with an employment history and mesothelioma were included, each matched

Table 1 Risks for lung cancer of different types of professional drivers

\begin{tabular}{|c|c|c|c|c|c|}
\hline \multirow[b]{3}{*}{ Occupational group } & \multirow[b]{3}{*}{ Cases/controls } & \multicolumn{4}{|c|}{ Socioeconomic adjustment } \\
\hline & & \multicolumn{2}{|l|}{ No } & \multicolumn{2}{|l|}{ Yes } \\
\hline & & OR & $95 \% C I$ & $O R$ & $95 \% C I$ \\
\hline $\begin{array}{l}\text { Employees other than } \\
\text { drivers }\end{array}$ & $26493 / 27329$ & 1 & & 1 & \\
\hline Lorry and bus drivers & $972 / 668$ & 1.47 & 1.32 to 1.64 & 1.31 & 1.17 to 1.46 \\
\hline Taxi drivers & $277 / 149$ & 1.85 & 1.39 to 2.46 & 1.64 & 1.22 to 2.19 \\
\hline Unspecified drivers & $1002 / 598$ & 1.62 & 1.51 to 1.74 & 1.39 & 1.30 to 1.51 \\
\hline
\end{tabular}

with 23 male controls with same year of birth and employment status.

INFORMATION ON TOBACCO SMOKING HABITS Data on tobacco smoking for the groups of drivers and other workers combined were taken from the files of two nationwide Danish surveys conducted in 1972 and 1982-3. The study populations consisted of, respectively, 4673 age stratified male members of 54 selected trade unions ${ }^{18}{ }^{19}$ and 2710 age stratified working male employees. ${ }^{20}{ }^{21}$ Both surveys were performed by administering structured questionnaires; the oldest data were collected by self administered questionnaire and the latest by face to face interviews. The average proportion of smokers was taken from a survey of 17739 economically active men in $1970-2 .^{22}$

\section{STATISTICAL ANALYSIS}

The socioeconomic status of each person, based on occupational title, was categorised into one of five groups according to the definitions developed by the Danish Institute of Social Sciences. ${ }^{23}$ The highest status, group 1, includes corporate managers and all academics; group 2 includes proprietors and managers of small businesses and teachers; group 3 includes technicians and nurses; group 4 includes skilled workers; and group 5 includes unskilled workers.

To respect the matched design of the study and to allow for adjustment for socioeconomic status, we estimated odds ratios (ORs) with their $95 \%$ confidence intervals ( $95 \%$ CIs) by conditional logistic regression analysis with the PECAN procedure in the statistical package EPICURE. $^{24}$ Tests for trends in risk by duration of employment were performed by including years of employment as a continuous variable in the logistic regression models. ${ }^{25}$ Exposure lagging by 10 years was used to allow for latency.

\section{Results}

\section{LUNG CANCER}

Table 1 shows the risks of lung cancer, with and without adjustment for socioeconomic status, for lorry and bus drivers, taxi drivers, and unspecified drivers. Significantly increased ORs were found for all types of driver. Decreases in the ORs of $11 \%-14 \%$ were found after adjustment for socioeconomic status for all groups.

Table 2 shows the risks of lung cancer for lorry or bus and taxi drivers according to duration of employment, adjusted for socioeconomic status. For both groups, a trend of increasing risk with increasing duration of employment was found $(\mathrm{p}<0.001)$. When a lag time of 10 years between diagnosis of lung cancer and first employment was included, the risk for lorry and bus drivers remained almost unchanged, whereas a tendency to increasing risk estimates was found for taxi drivers. Thus, an OR of 3.0 (95\% CI 1.2 to 6.8) was found for taxi drivers who had been working for more than five years. 
Table 2 Risks for lung cancer of bus and lorry drivers and taxi drivers after adjustment for socioeconomic status by duration of employment and lag time*

\begin{tabular}{|c|c|c|c|c|c|c|}
\hline \multirow[b]{2}{*}{ Duration of employment } & \multicolumn{3}{|c|}{ Lorry and bus driver } & \multicolumn{3}{|c|}{ Taxi driver } \\
\hline & $O R$ & $95 \% C I$ & $\begin{array}{l}p \text { Value test } \\
\text { for trend }\end{array}$ & $O R$ & $95 \% C I$ & $\begin{array}{l}p \text { Value test } \\
\text { for trend }\end{array}$ \\
\hline \multicolumn{7}{|l|}{ No lag time: } \\
\hline$<0.5 \mathrm{y}$ & 1.0 & 0.8 to 1.3 & & 0.7 & 0.4 to 1.2 & \\
\hline $0.5-1 \mathrm{y}$ & 1.3 & 0.9 to 1.7 & & 1.6 & 0.8 to 3.2 & \\
\hline $1-5 y$ & 1.4 & 1.1 to 1.6 & $<0.001$ & 1.7 & 1.0 to 2.9 & $<0.001$ \\
\hline$>5 \mathrm{y}$ & 1.4 & 1.1 to 1.7 & & 2.2 & 1.1 to 4.7 & \\
\hline \multicolumn{7}{|l|}{10 year lag time: } \\
\hline$<0.5 \mathrm{y}$ & 1.1 & 0.9 to 1.4 & & 1.0 & 0.5 to 1.7 & \\
\hline $0.5-1 \mathrm{y}$ & 1.2 & 0.8 to 1.6 & & 1.6 & 0.8 to 3.4 & \\
\hline $1-5 y$ & 1.4 & 1.1 to 1.7 & $<0.001$ & 1.8 & 1.0 to 3.2 & $<0.001$ \\
\hline$>5 \mathrm{y}$ & 1.4 & 1.1 to 1.8 & & 3.0 & 1.2 to 6.8 & \\
\hline
\end{tabular}

* Time between first employment and diagnosis.

Table 3 Risk for pleural mesotheliomas among different types of drivers, adjusted for socioeconomic status

\begin{tabular}{llll}
\hline Occupational group & Cases/controls & OR & $95 \%$ CI \\
\hline Employees other than drivers & $513 / 11524$ & 1 & \\
Lorry and bus drivers & $18 / 532$ & 0.6 & 0.4 to 1.0 \\
Taxi & $4 / 128$ & 0.7 & 0.3 to 1.9 \\
Unspecified & $15 / 466$ & 0.7 & 0.4 to 1.2 \\
\hline
\end{tabular}

Table 4 Tobacco smoking habits of male drivers and all economically active men

\begin{tabular}{lllll}
\hline & & & \multicolumn{2}{c}{ Prevalence (\%) } \\
\cline { 5 - 5 } Group & Period & $\begin{array}{l}\text { Men } \\
\text { interviewed (n) }\end{array}$ & Smoker & $\begin{array}{l}\text { Heavy } \\
\text { smokers* }\end{array}$ \\
\hline Drivers & 1972 & 255 & 73 & ND \\
Drivers & 1983 & 197 & ND & 34 \\
Economically active men & $1970-2$ & 17739 & 72 & 27 \\
\hline
\end{tabular}

^ Smokers of more than 15 cigarettes per day. ND = no data.

\section{MESOTHELIOMAS}

Table 3 shows the risk for mesothelioma. Nonsignificantly decreased risks $(0.6-0.7)$ were found for all three groups of drivers.

\section{SMOKING HABITS}

Table 4 shows the tobacco smoking habits of Danish drivers and of all economically active men; it is based on survey data. In the survey of 1972 , about $73 \%$ of all drivers were smokers; in 1983 , about $34 \%$ of the drivers were heavy smokers. In $1970-2$, about $72 \%$ of all economically active men were smokers, and $27 \%$ were heavy smokers.

\section{Discussion}

This nationwide study including 2251 bus, lorry, taxi, and unspecified male drivers with primary lung cancer showed a $31 \%-64 \%$ excess risk compared with other employees in Denmark, after adjustment for socioeconomic differences. Increased risks of around the same size have been reported in smaller studies. ${ }^{1626-32}$

Observational bias is unlikely in this study, because the exposure definition is based on routine registration of work histories, independent of the cancer diagnosis. The possibility that some of the drivers had previous jobs in which they were more heavily exposed to lung carcinogens is speculative, and no more likely than for other subjects included in the unexposed control group.

Interpretation of occupational studies on lung cancer depends on the handling of tobacco smoking as a confounder. No direct information was available on individual tobacco smoking habits in this study; however, the prevalence of tobacco smoking among men in Denmark is generally high: about $72 \%$ of the Danish men were smokers in 1970-2, and about $27 \%$ were heavy smokers, $(>15$ cigarettes per day). There would therefore have to be a substantially higher proportion of smokers among Danish drivers than in the general employed population to explain even a slight increase in risk of lung cancer. That seems not to be the case. Also, the relative risks were adjusted for socioeconomic status, which is strongly correlated with tobacco smoking in Denmark. ${ }^{33}$ Finally, the risk of lung cancer was found to increase with duration of employment as a professional driver, which is unlikely to be due to the confounding effect of tobacco smoke alone. ${ }^{34}$ Another major potential confounder, asbestos exposure, did not seem to contribute to the increased risk of lung cancer, as the risk of mesotheliomas, which is probably caused only by asbestos, ${ }^{17}$ was below that expected for all groups of drivers.

Exposure of drivers to markers of air pollution related to traffic has been measured in several studies. The average concentration of carbon monoxide (CO) to which vehicle commuters in Los Angeles were exposed was approximately $10 \mathrm{ppm}$, whereas the exposures at home, at work, and at the nearest outdoor, fixed site monitoring station were two to three times lower. ${ }^{6}$ The exposure of lorry drivers to elemental carbon particulate, a marker of diesel exhaust, was $5.1-5.4 \mu \mathrm{g} / \mathrm{m}^{3}$, which was about four times higher than the outdoor concentrations in residential areas. ${ }^{7}$ Local lorry drivers in the Geneva area were exposed to two to three times higher concentrations of dust in their vehicles $\left(0.3 \mathrm{mg} / \mathrm{m}^{3}\right)$ than long distance drivers and to two to seven times higher concentrations of polycyclic aromatic hydrocarbons (38$\left.100 \mathrm{ng} / \mathrm{m}^{3}\right) .{ }^{9}$ The category of vehicle also seems to be important in exposure: Washington car commuters were exposed to 9-14 ppm CO and bus commuters were exposed to $4-8 \mathrm{ppm} \mathrm{CO}$, whereas rail commuters were exposed to $2-5$ ppm CO. ${ }^{11}$ Similar results were reported for commuters in Paris. ${ }^{12}$ The average exposure of Boston car commuters to $\mathrm{CO}$ was $13.4 \mathrm{ppm}$, whereas that of train and bus commuters was 7.4 ppm. ${ }^{10}$ Moreover, the concentrations of traffic exhaust fumes decrease with increasing height above street level. Raising the sampling height from 1.7 to $4.6 \mathrm{~m}$ in downtown urban streets decreased the $\mathrm{CO}$ concentration by $5 \%-15 \%,{ }^{10}$ which would tend to generate higher concentrations in cars, including taxis, than in lorries and buses. The importance of the height of the vehicle's air intake was confirmed in a French study. ${ }^{35}$ Thus, high traffic density on the streets, intense urbanisation, and a greater prevalence of cars (including taxis) than buses or lorries result in greater exposure of drivers to traffic exhaust fumes.

In occupational studies, duration of employment and differences in exposure levels within the same occupational group are common ways of estimating dose. ${ }^{36}$ We found a significantly increasing risk by duration of employment among taxi, bus, and lorry drivers, and a 
tendency to a higher risk among the group with highest exposure - that is, taxi driverssuggesting an aetiological role for exposure to exhaust with respect to risk of lung cancer.

1 Bates DV. Adverse health impacts of air pollution: continuing problems. Scand $\mathcal{F}$ Work Environ Health 1995;21:40511 .

2 International Agency for Research on Cancer. IARC monographs on the evaluation of carcinogenic risks to humans. Polynuclear aromatic compounds, engine exhausts and nitroarenes. Vol 46. Lyon: International Agency for Research on Cancer, 1989.

3 Raaschou Nielsen O, Nielsen ML, Gehl J. Traffic-related air pollution: exposure and health effects in Copenhagen street cleaners and cemetery workers. Arch Environ Health 1995 50:207-13.

4 Godin G, Wright G, Shephard RJ. Urban exposure to carbon monoxide. Arch Environ Health 1972;25:305-13.

5 Weisel CP, Lawryk NJ, Lioy PJ. Exposure to emissions from gasoline within automobile cabins. I Expo Anal Environ Epidemiol 1992;2:79-96.

6 Ziskind RA, Fite K, Mage DT. Pilot field study: carbon monoxide exposure monitoring in the general population. monoxide exposure monitoring

7 Zaebst DD, Clapp DE, Blade LM, et al. Quantitative determination of trucking industry workers exposures to diese exhaust particles. Am Ind Hyg Assoc F 1991;52:529-41.

8 Chang-Chuan C, Özkaynak H, Spengler JD, et al. Driver exposure to volatile organic compounds, CO, ozone, and
$\mathrm{NO}_{2}$ under different driving conditions. Environ Sci Technol 1991;25:964-72.

9 Guillemin MP, Herrera H, Huynh CK, et al. Occupational exposure of truck drivers to dust and polynuclear aromatic hydrocarbons: a pilot study in Geneva, Switzerland. In Arch Occup Environ Health 1992;63:439-47.

10 Cortese AD, Spengler JD. Ability of fixed monotoring stations to represent personal carbon monoxide exposure. $f$ Air Pollut Control Assoc 1976;26:1144-9.

11 Flachsbart PG, Mack GA, Howes JE, et al. Carbon monoxide exposures of Washington commuters. F Air Pollut Con ide exposures of Washington
trol Assoc 1987;37:135-42.

12 Dor F, Le Moullec Y, Festy B. Exposure of city residents to carbon monoxide and monocyclic aromatic hydrocarbons during commuting trips in the Paris metropolitan area. fournal of the Air

13 Storm HH, Pihl J, Michelsen E, et al. Cancer incidence in Denmark 1993. Copenhagen: Danish Cancer Society, 1996.

14 Olsen JH, Jensen OM. Occupation and risk of cancer in Denmark. An analysis of 93810 cancer cases, 1970-9. Scand 7 Work Environ Health 1987;13(suppl 1):1-91.

15 Danmarks Statistik. Danmarks Statistik Erhvervsgrupperingskode, DSE 77. København: Danmarks Statistik, 1989.

16 Borgia P, Forastiere F, Rapiti E, et al. Mortality among taxi drivers in Rome: a cohort study. $A m$ f Ind Med 1994;25:507-17.

17 International Agency for Research on Cancer. IARC monographs on the evaluation of the carcinogenic risk of chemicals to humans. Abestos. Vol 14. 1977;1-106.
18 Redder KW, Svane O, Westergård P. The work enviroment survey. Copenhagen: the Danish National Institute of Social Research, 1974;1-208.

19 Danish Data Archives. The work environment survey, 1973. Odense: Danish Data Archives, 1982;1-130.

20 Ørhede E, Nielsen S. The work environment survey, 1983. Odense: Danish Data Archives, 1990;1-106.

21 Ørhede E, Nielsen S. Screening of working environment. An interview survey of a representative sample of the work force. Copenhagen: Arbejdsmiljøinstituttet, 1986;1-184.

22 Engholm G, Palmgren F, Lynge E. Lung cancer, smoking, and environment: a cohort study of the Danish population. BM7 1996;312:1259-63.

23 Hansen EJ. Socialgrupper $i$ Danmark. Copenhagen: The Institute of Danish Social Science, 1984

24 Preston DL, Lubin JH, Pierce DA, et al. Epicure. Seattle: HiroSoft, 1996.

25 Breslow NE, Day NE. Statistical methods in cancer research. Vol I. The analysis of case-control studies. Lyon: IARC, 1980.

26 Gubéran E, Usel M, Raymond L, et al. Increased risk for lung cancer and for cancer of the gastrointestinal tract among Geneva professional drivers. Br f Ind Med 1992;49: $337-44$

27 Boffetta P, Stellman SD, Garfinkel L. Diesel exhaust exposure and mortality among males in the American Cancer Society prospective study. Am f Ind Med 1988;14:403-15.

28 Steenland K, Silverman D, Zaebst DD. Exposure to diesel exhaust in the trucking industry and possible relationships with lung cancer. Am f Ind Med 1992;21:887-90.

29 Steenland K, Silverman D, Hornung R. Case-control study of lung cancer and truck driving in the Teamsters Union. Am $\mathcal{F}$ Public Health 1990;80:670-4.

30 Burns PB, Swanson GM. The occupational cancer incidence surveillance study (OCISS): risk of lung cancer by usual occupation and industry in the Detroit metropolitan area. Am f Ind Med 1991;19:655-71.

31 Keller JE, Howe HL. Risk factors for lung cancer among non-smoking Illinois residents. Environ Res 1993;60:1-11.

32 Jakobsson R, Gustavsson P, Lundberg I. Increased risk of lung cancer among male professional drivers in urban but not rural areas of Sweden. Occup Environ Med 1997;54: 189-93.

33 Osler M. Smoking habits in Denmark from 1953 to 1991: a comparative analysis of results from three nationwide health surveys among adult Danes in 1953-4, 1986-7, and 1990-1. Int f Epidemiol 1992;21:862-71.

34 Siemiatycki J, Wacholder S, Dewar R, et al. Degree of confounding bias related to smoking, ethnic group, and socioeconomic status in estimates of the associations between occupation and cancer. F Occup Med 1988;30: $617-25$

35 Limasset JC, Diebold F, Hubert G. Exposition des conducteurs de bus urbains aux polluants de la circulation automobile. (Exposure of urban bus drivers to traffic pollution.) Sci Total Environ 1993;134:39-49.

36 Checkoway H, Pearce NE, Crawford-Brown DJ. Research methods in occupational epidemiology. New York: Oxford University Press, 1989. 